\title{
SUPLEMENTO CULTURAL A SERVIÇO DA COMUNIDADE
}

\section{Caderno de Encartes do Jornal de Natal é exemplo}

de perseverança e autonomia, rema contra a maré concentracionista dos meios de comunicação, cada vez mais comprometidos com o poder político e econômico

A experiência que tivemos nos últimos dois anos na editoria do Caderno de Encartes, suplemento cultural do Jornal de Natal, semanário que circula às segundas-feiras na capital e em 80 cidades do Rio Grande do Norte, com cerca de 5 mil exemplares, nos possibilitou vivenciar, no dia-a-dia, as absolutas alegrias e desesperos que um laboratório de carências e insuficiências pode oferecer.

Levando-se em conta que esse laboratório é do chamado terceiro mundo, incrustado numa das regiões mais pobres de um país chamado Brasil, pode-se imaginar o que queremos dizer.

Para compreender o gozo gozoso que, apesar de tudo, se pode viver neste labor, para incorporar uma expressão/vivência do teatro de José Celso Martinez Corrêa, deve-se observar que a precariedade, como tom dominante do trabalho para fazer o suplemento, evidencia-se a partir do próprio nome do suplemento/laboratório: Caderno de Encartes, que faria as delícias, por exemplo, dos requisitos acadêmicos de um mestre como José Marques de Melo, professor da ECA-USP e um dos pioneiros da pesquisa em comunicação no país.

A idéia original do nome implicaria apenas a junção da palavra encarte, como caderno mesmo, de cultura e arte, numa junção com a palavra arte, que culminou - e consagrou-se, ao final - com a permanência redundante dos dois nomes e assim ficou, como só ocorre com a provisoriedade brasileira que se eterniza... O nome, portanto, seria apenas Enc/Artes, com o qual preferimos nomear o suplemento, para suavizar o vexame da redundância.

Uma breve olhada na imprensa do Estado, de maneira geral, tendo-a doravante sempre como pano de fundo, permite aquilitar a extensão e significado do trabalho que vem sendo desenvolvido no Encartes e

\section{O AUTOR}

Paulo Augusto da Silva

Jornalista, ex-editor do Caderno de Encartes, suplemento cultural do Jornal de Natal, RN. 
em suas investidas como oficina no setor, ressalvando-se sempre sua precariedade.

Para situar os leitores de outras regiões do Brasil, poderíamos citar, em termos de comparação com a televisão, a audiência média de 42 pontos do Jornal Nacional, da Rede Globo, contra os dez pontos obtidos pelo TJ Brasil, do SBT, apresentado por Hermano Henning, quando da transferência do âncora Boris Casoy do $S B T$ para a Record, em julho de 97, quando o Jornal da Record oscilou, no primeiro dia do homem do bordão "Isso é uma vergonha!" na nova emissora, entre sete e dois pontos.

O Jornal de Natal, em seu formato tablóide e edição em preto e branco, sem recursos tecnológicos e apoio de infra-estrutura, com carências em termos técnicos e humanos, estaria mais para Casoy do que para a pausterização do padrão Globo de qualidade. Quando comparado com os dois diários da Capital potiguar Tribuna do Norte, do ex-governador do RN, ex-ministro da administração (governo Sarney) e ex-deputado federal Aloísio Alves, e o Diário de Natal, dos Diários Associados, com forte influência do poder econômico dos que fazem a política potiguar, ambos sustentando o status quo local - serve como comparação e contraponto por sua vivacidade, insolência e seu caráter subversivo, apesar do efeito apenas residual sobre a opinião pública do Rio Grande do Norte. Portanto, cumpre um papel, mesmo diante da avalanche representada pela mídia avassaladora dos coronéis da política que, como senadores, deputados, governadores, prefeitos e vereadores, possuem ampla penetração e audiência graças à obtenção de concessões de suas emissoras de televisão, suas rádios e seus jornais abusadamente coloridos e estapafúrdios.

\section{PEDRA NO SAPATO}

Para efeito de entendimento do caráter de resistência do Jornal de Natal nesse contexto, é digna de nota a postura expressa (com seu cinismo explícito) do presidente do Sindicato das Empresas de Comunicação do RN, Haroldo Azevedo (empresário da construção civil), representante da classe patronal, ao cercear o trabalho das rádios comunitárias no Estado, classificando-as como "rádios piratas", que "geram anarquia", "agravando o quadro de banditismo e marginalidade a que o país assiste hoje", quando, na realidade, a maioria dos políticos possuem suas próprias rádios na Capital e no Interior do Estado.

Vale ressaltar que o Jornal de Natal surgiu a 8 de maio de 1989, com a união de esforços de um jornalista - que partiu para o 
investimento como um microempresário e que voltaria para a mídia estandardizada e comprometida com o status quo após essa incursão -, um médio empresário do setor gráfico e um empresário que entrou na sociedade com a sede do tablóide. Nos dois primeiros anos o veículo praticou um jornalismo chapa branca, apenas de exaltação e registro dos atos oficiais e de fait divers (acontecimentos cotidianos), para transformar-se na pedra no sapato do establishment nos últimos sete anos, com todas as agruras das represálias decorrentes da atitude, sofrendo o boicote das agências de publicidade e de anunciantes avulsos comprometidos com o poder.

\section{O TRAMPOLIM DA VITÓRIA OU A GALINHA DOS OVOS DE OURO}

Natal, capital do Rio Grande do Norte, com seus pouco mais de 600 mil habitantes - 668.119 (1995) -, como boa província, pretende ser sempre a mais avançada, em termos de comportamento e de usos e costumes, em meio às capitais da Região Nordeste. Contribui para isto o fato de ter transitado pela cidade, durante a Segunda Guerra Mundial, um contingente de cerca de dez mil soldados norte-americanos e de outras nacionalidades, com todas as conseqüências naturais de uma invasão que, contudo, não ousa dizer o nome.

Este período foi reconstituído no filme For All, o trampolim da vitória, de Luís Carlos Lacerda e Buza Ferraz, lançado na $25^{\mathrm{a}}$ edição do Festival de Gramado, ocorrido no início de agosto de 1997.

$\mathrm{Na}$ verdade, a Capital potiguar sofreria, com a invasão norte-americana, um verdadeiro estupro cultural, de que até hoje se vêem resquícios.

Se observamos a sua conexão com o mundo, verificamos que, em 1939, poucos eram os que possuíam aparelho de rádio, privilégio dos ricos, apontando-se nominalmente as famílias natalenses que dispunham de rádio-receptor. A cidade, no dizer de um cronista da época, "não tinha pressa para crescer e essa tranqüilidade fazia prolongar a vida de seus habitantes, que mantinham hábitos moderados, comportamento morigerado". Vale a pena acompanhar a cena da cidade no final da década de 30, descrita por José Nazareno Moreira de Aguiar, no livro de crônicas Cidade em black out, cujo sistema de vida dos 50 mil habitantes era "o de dormir e acordar cedo": 
"Colocavam cadeiras nas calçadas para ouvir e contar 'estórias' de assombração, de alma de outro mundo, pois a crendice estava arraigada entre gente simples. As crianças adoravam a lenda da Galinha dos ovos de ouro, que aparecia e se 'encantava' nos morros que circundam a cidade, enquanto os adultos se emocionavam com as peripécias das burras-de-padre, dos lobisomens. As mulheres atemorizavam-se com os relatos de assaltos praticados pelo negro-melado ou ataques dos papa-figos, que roubavam criancinhas para sacrificá-las em favor da saúde dos leprosos. Acreditavase nas 'estórias' fantásticas de pescadores seduzidos por mães d'água ou arrebatados por lindíssimas sereias, vibrando-se de entusiasmo pela descrição de lutas travadas entre pescadores e peixes monstruosos, polvos de mil tentáculos, arraias gigantescas... Não havia preocupações com problemas domésticos, nem se ligava aos martirizantes preconceitos sociais. Tudo era livre, de simplicidade cativante, não se dando guarida à maledicência. E logo depois do relógio da velha matriz badalar nove horas, todos se recolhiam, pois o sistema de vida daquelas cinqüenta mil pessoas era o de dormir e acordar cedo"'.

Com a repercussão da concordância de Getúlio Vargas para que os americanos desembarcassem em Natal, logo após a declaração do estado de guerra entre o Brasil e as potências do eixo (Alemanha, Itália e Japão), Natal viu-se transformada em uma verdadeira Babel, com impressionante movimento de tropas.

"Nunca uma variedade de raças e profissões havia se concentrado num só ponto do território nacional, com a permanência ou trânsito de soldados norte-americanos, aviadores britânicos, fuzileiros filipinos, marinheiros franceses, diplomatas de diversas nacionalidades, padres católicos e pastores protestantes, policiais, agentes do serviço de contra-espionagem, artistas de cinema e de rádio, jornalistas, médicos, enfermeiros, assistentes sociais etc."2.

A cidade ganharia inclusive o epíteto de Trampolim da Vitória, por conta do aeroporto mandado construir às pressas em Parnamirim, cidade que passaria muitos anos conhecida como Eduardo Gomes, em razão de um preito de gratidão ao então brigadeiro, só recentemente, através de plebiscito, voltando ao seu nome original.

$\mathrm{Na}$ atualidade, com relação à infra-estrutura montada em termos de comunicação, pode-se dizer que, não fugindo ao figurino coronelístico nordestino, talvez apenas os Correios e a Internet ain-

1. AGUIAR, José Nazareno de. Cidade em black out. Natal: UFRN-Editora Universitária, 1991.

2. Idem. ibid. 
da não sejam de domínio das oligarquias, mantidas pelo baronato detendor do poderio político-econômico, cujos bankers (banqueiros) comandam, cada qual em seu barril, as freguesias habitadas, a partir da Capital.

Para dizer a verdade, refletindo a realidade nacional, onde se constata o domínio de oito ou dez famílias sobre as redes de televisão, de rádio e jornais, o Rio Grande do Norte apresenta um quadro bastante característico, com duas famílias predominantes.

Há cerca de 40 anos a oligarquia dos Alves e dos Maia - a primeira, família remanescente de esquemas montados pela política do cabresto oriunda da República Velha (1889-1930), a segunda, oligarquia que ascendeu com patrocínio da ditadura (1964) - comandam o espectro político local, sendo, portanto, proprietárias e concessionárias de todo o aparato tecnológico relativo à mídia potiguar.

Competem com as duas, três ou quatro nomes que chegaram à política no rastro das famílias hegemônicas, carregados de compromissos e fidelidade, tendo se arranjado igualmente no que diz respeito a munir-se de meios de comunicações, com os quais azeitam seu poder e acumulam e concentram riquezas, mantendo intacto o status quo que caracteriza a vida natalense praticamente desde a fundação da República.

Assim é que, espraiando-se pelo Interior, aos mais recônditos e distantes grotões, a comunicação produzida e consumida tem como matriz a ideologia de oligarquias que, evidentemente, não pretendem tão cedo perder seus anéis...nem seus dedos.

\section{A MALHA DA COMUNICAÇÃO E A LUTA PELA TELEVISÃo COMUNITÁRIA}

Assim é que a família Alves, com o ex-ministro Aloísio Alves à frente, como il cappo de tutti capi, dispõe de um jornal, Tribuna do Norte, uma concessão de televisão, filiada à Rede Globo, TV Cabugi e um pool de rádios no interior, postas à disposição do fiIho do deputado federal, Henrique Eduardo Alves, ambos do PMDB. Entre as rádios se destacavam, até recentemente, as rádios Cabugi AM e Transamérica FM (Natal), a Cabugi do Seridó AM (sediada em Jardim do Seridó), a Difusora AM (em Mossoró, segunda cidade do Estado), e a 104 FM (em Parnamirim, com concessão dada a um parente influente, primo e ex-prefeito de Natal Agnelo Alves). 
O ex-governador e atual senador José Agripino Maia, braço do PFL no Estado, estrela maior da oligarquia concorrente, possui a TV Tropical (filiada ao grupo Manchete) e as rádios AM e FM (Natal), a rádio Salinas (Macau), Libertadora AM (Mossoró), Ouro Branco AM (Currais Novos), a Voz do Seridó AM (Caicó), Tropical Curimataú AM (Nova Cruz) e rádio Cultura (Paus dos Ferros, no Alto Oeste, fechando o cerco nas cidades-pólo de todo o Estado).

A partir deste tronco, registram-se mais duas famílias que dominam os outros dois canais de televisão, por concessão obtida em Brasília exatamente por meio dos cabeças das famílias, transformados em senador e deputado, como é o caso do ex-governador, hoje senador Geraldo Melo (TV Pontegi) e do ex-senador e atual deputado federal Carlos Alberto de Souza (TV Ponta Negra). Contando-se daí, é comum aos oito deputados federais terem ao seu dispor rádios e jornais para suas boutades e desmandos.

Deduz-se desse quadro que a rede de comunicação social do Estado, que deveria informar e formar o norte-rio-grandense, passa pelo filtro das famílias dominantes, que repassam e transmitem apenas o que thes aprouver, no sentido de manterem intacto seu poder, um ancien régime que remonta à fundação da República no Estado potiguar.

As tentativas das comunidades que lutaram ao longo dos anos pela conquista de canais livres da censura e do figurino das informações veiculadas pela malha dominante, quando tentaram criar, fundar e fazer funcionar seus canais próprios para informarem-se correta e salutarmente, através de emissoras de rádios e TVs comunitárias, foram rechaçadas e regrediram ao ponto de partida, acusadas, pelos oligarcas, de emissoras fantasmas ou piratas e enquadradas, na forma de legislação por eles criadas e brandidas - fugindo, inclusive, ao que legisla a própria Constituição Federal -, como emissoras fora da lei. Assim é que, em junho de 1996, o Sindicato das Empresas de Comunicação do RN, entidade patronal responsável pela vigilância nos meios de comunicação potiguares, através de seu presidente, o empreiteiro Haroldo Azevedo, obstaculou os anseios e as necessidades de comunicação entre si dos homens e mulheres potiguares, alegando que tais rádios "geravam anarquia, agravando o quadro de banditismo e marginalidade a que o país assiste hoje", passando por cima do tratado assinado pelo Brasil na Costa Rica reconhecendo as rádio: comunitárias. Televisão comunitária, então, é uma utopia que só existe muito além do horizonte do espectador-eleitor potiguar, coisa de que se ouve falar quando se lê nos jornais do Sul acerca de algumas poucas emissoras a cabo trabalhadas por entidades do Rio de Janeiro, São Paulo e do extremo Sul do país. 


\section{EXPERIÊNCIA DO JORNAL DE NATAL NOS SEUS NOVE ANOS}

Nesse contexto, surgiu, há nove anos, o Jornal de Natal, a mais longa e venturosa experiência das comunicações alternativas no Rio Grande do Norte, cultivando a experiência do jornalismo independente e investigativo com jornalistas que então iniciavam suas carreiras no mercado local.

Tendo em vista que o Encartes é o suplemento cultural de um jornal carente, feito com dificuldades e em virtude de sua periodicidade semanal, não se qualifica, a priori, como um caderno de serviço, como os que vão encartados nos jornais da chamada grande imprensa ou imprensa burguesa local. Não pretende, portanto, ser indicativo ou antecipativo. Explora seletivamente os produtos culturais que seu leitor possa consumir e, de forma restrita, agenda eventos a ocorrer no período. Nesse sentido, trabalha mais com reportagens e comentários críticos posteriores aos eventos, complementando o acesso físico e intelectual do leitor aos produtos culturais em pauta.

Devido à ausência de um corpo de repórteres, o Encartes optou por um jornalismo comunitário, aceitando e estimulando a remessa por parte dos leitores de opiniões e comentários que ultrapassam o simples espaço ou configuração de uma carta do leitor, publicando artigos, críticas, análises e até ensaios de seu consumidor, que se transforma em produtor do próprio caderno de jornalismo.

A partir deste enfoque, o Encartes ganha uma feição absolutamente diferente de seus concorrentes no setor, em Natal, por transformar-se em uma referência e uma oportunidade para cada um dos seus leitores, que nele podem interferir/intervir, participando efetivamente do fazer cultural.

\section{PROMOCÕES E ESTÍMULOS \\ PARA A COMUNIDADE \\ DE ARTISTAS LOCAIS}

O Encartes, ao longo desses dois últimos anos de experiência, passou a colaborar com a comunidade de artistas local e com a população em geral, propiciando oportunidades para que fossem apresentadas, através de concursos e de abertura de espaço, as propostas dos que fazem arte e cultura ou daqueles que a apreciam, sem 
condições de participar/intervir no fazer cultural a partir da instância oficial.

Assim é que, concorrendo com os próprios órgãos culturais oficiais, demasiadamente lerdos no fazer/propiciar oportunidades, o Encartes, entre outros eventos, realizou:

1. Abertura de uma página mensal para fotografia, sob o título O Estado em Ensaio, publicando um fotógrafo de cada vez, com cinco fotografias por ele realizadas, uma foto do autor e um pequeno perfil do autor.

2. Criação de uma página para poetas, denominada Poesiativa do Encartes, sem qualquer tipo de discriminação, permitindo o acesso dos que fazem versos no Estado. O Poesiativa do Encartes, no decorrer do primeiro ano de existência, comemorado a 18 de agosto de 1997, como era de esperar, terminou transformando-se num suplemento do próprio Encartes, em razão do acúmulo de poesias enviadas, com cartas de simpatia e estímulo oriundos dos mais diversos pontos do Estado.

No Dia Nacional da Poesia, comemorado a 14 de março, o Poesiativa do Encartes pôde circular com ampla amostra da poesia produzida no Estado, com espaço aberto a todos os artistas, tendo obtido a melhor repercussão na cidade.

3. Em setembro de 1996, criou um Concurso de Contos, os melhores foram premiados, com brindes aos três primeiros colocados e livros para os dez melhores e publicação posterior nas páginas do Caderno. A primeira experiência rendeu ótima repercussão.

4. Em abril de 1997, lança o I Salão de Encartes do Humor, voltado para cartunistas do Estado, com brindes oferecidos pelo comércio local para os três primeiros colocados e livros para os dez melhores. Provocou boa repercussão, recebendo inscrição de cartunistas/artistas já consagrados, além de muitos principiantes. A entrega dos prêmios, na Casa do Estudante do Rio Grande do Norte, e a publicação posterior dos dez primeiros colocados, têm despertado o interesse dos chargistas e cartunistas locais.

O I Salão Encartes do Humor percorreu o Centro Popular João Ricardo, entidade de defesa dos direitos humanos, localizada no Conjunto Santa Catarina, Zona Norte, onde se inaugurou a exposição. Ela também foi exibida no SESC/Restaurante da Cidade Alta, e na Escola de Primeiro e Segundo Graus Fundação Bradesco, localizada no bairro de Felipe Camarão, na periferia de Natal.

5. A criação da seção HQ Potiguar, entregue a cartunistas e desenhistas de Natal, com os artistas Rooney Figueiredo e Anderson Leão à frente, possibilitou a transformação da última página do Encartes em espaço especialmente dedicado às histórias em quadrinhos e notícias sobre o mundo dos cartuns, permitindo a vei- 
culação da produção de cartuns e HQs criados por artistas locais, com regularidade.

6. O caderno criou um espaço denominado Canto Glossado, quinzenal, um gênero literário pouco estimulado mas grandemente apreciado no Nordeste, para publicação de glosas de autores locais ou de fora do Estado, sendo publicado há cerca de seis meses.

7. A criação da seção Iluminismo no Sertão, para publicação semanal do comentário, artigo ou reportagem sobre a situação da cultura em cada município do Estado obteve certa repercussão, tendo sido publicados comentários/artigos de, pelo menos, cinco das maiores cidades do Estado, em razão da conexão do Caderno com artistas dessas cidades. A suspensão da seção, que não quer dizer sua extinção, mantém-se por ausência de contato com pessoas explicitamente interessadas em escrever, levando-se em conta a natural timidez dos artistas/escritores em se expor criticamente diante das autoridades de pequenas comunidades.

8. O caderno criou ainda a Sacação, dedicada a fotoflagrante, com exibição semanal de fotos feitas por fotógrafos e repórteres-fotográficos locais.

9. Em outubro de 1996, o Caderno de Encartes criou o Projeto Oficina da Arte, levando às comunidades a oportunidade de os artistas locais apresentarem seus trabalhos. Para tanto, a iniciativa reúne a contribuição do comércio local da área escolhida, a fim de possibilitar a oferta de uma infra-estrutura mínima - como palco e som, painéis para mostra de artes plásticas e poesia-varal -, recorrendo à Prefeitura e ao governo do Estado para garantir iluminação e segurança. Em novembro de 1996, realizou-se, na Praça das Flores, dentro da praça Aristófanes Fernandes, no bairro do Tirol, nas tardes/noites da sexta-feira e sábado, a I Oficina da Arte, reunindo expressivo número de poetas, músicos, cantores/compositores, artistas plásticos, mímicos, fotógrafos, grupos de dança, a maioria sem acesso à mídia ou a eventos sociais, praticamente inexistentes ou de difícil acesso a amadores e a principiantes.

10. A criação da seção Roda da Palavra, espaço para comentários/críticas de livros pelos próprios leitores, iniciada em maio de 1996, possibilitou, na primeira experiência, a publicação de 15 artigos/críticas de autoria de estudantes, donas-de-casa, operários e artistas, de modo geral, sobre o tema Dignidade, baseado no livro $O$ homem medíocre, do filósofo e escritor argentino José Ingenieros (1877-1925). Em parceria com a Livraria do Chain Editora, de Curitiba (PR), que traduziu e colocou no mercado a obra, o Encartes pôde oferecer um exemplar do livro a cada um dos participantes, numa iniciativa adotada e estimulada pela editora paranaense. 
11. A seção Trovariedade, de responsabilidade da Academia de Trovas do Rio Grande do Norte, tendo à frente, como responsável, o trovador Severino Campêlo, prossegue sua publicação única no Estado, há mais de cinco anos.

12. Criação do Conselho da Cidade, seção que teve início em maio, discutindo o tema Orçamento Participativo por membros da comunidade Macau, cidade salineira do Estado, e que se estendeu por quatro meses, reunindo desde o pároco local a vereadores, operários da indústria salineira, professores da rede pública, profissionais liberais e artistas, além de munícipes e contribuintes em geral, interessados na implantação e participação mais efetiva num orçamento discutido e analisado pela comunidade. Esse debate prossegue nas páginas do Encartes, sob a coordenação do responsável pelo jornal alternativo Volante Operário, João Eudes Gomes, de Macau. A criação dessa tribuna no Encartes trouxe a possibilidade de um diálogo com o prefeito de Macau e demais autoridades.

13. Dentre as atividades permanentes do Encartes, têm-se atendido solicitações para palestras em comunidades, colégios e entidades comunitárias. Como registro, contam-se debates com alunos da UMES - União Metropolitana de Estudantes Secundaristas, palestra sobre imprensa para Grupo de Idosos do Sesc, participação no Seminário Ética, violência e impunidade, patrocinado pelo Sindicato dos Jornalistas Profissionais no Rio Grande do Norte (Sindjorn).

Acreditamos que o Encartes, como suporte, tem contribuído para o surgimento de um leitor mais crítico e mais consciente da problemática nacional, informando-se e informando não apenas sobre aquilo que se passa na vertente cultural, mas abrindo um amplo leque de opção de leituras e de intervenção do leitor. A melhor qualificação do leitor, no intercâmbio com outros leitores e outras realidades, é a proposta a que tem se dedicado o Caderno de Encartes.

\section{O CADERNO E SUA GEOGRAFIA}

O Caderno de Encartes varia em número de páginas, saindo com doze e, eventualmente, circulando com dez e até oito páginas. A distribuição de seções segue o padrão estabelecido há cerca de dois anos, com uma reportagem de capa e seções fixas, como Canto de Natal (p.2), enfocando uma personalidade local, com traços biográficos e perguntas sobre como vê a cidade; Cinema (p.2), Agenda de Eventos e Livros (p.3); coluna Balão de Ensaio, do editor, a primeira a apresentar crítica sistemática sobre as oligarquias, cujos artigos renderam o livro Estilhaços de um país-Geni ${ }^{3}$; coluna Ciência 
e Tecnologia, do Prof. da UFRN, Ari Antônio da Rocha (p.4); Horóscopo; coluna Socialtur, de sociedade e turismo, a cargo da colunista social Liege Barbalho; coluna Trovariedades, a cargo da Academia de Trovas do Rio Grande do Norte; coluna Hype, com notícias do universo jovem, a cargo do colunista Sílvio Santiago; e HQ Potiguar, que ocupa toda a página 12, com notícias da área de quadrinhos e tiras permanentes, a cargo dos desenhistas Rooney Figueiredo e Anderson Leão (responsáveis pela página), Vieira, Joab e Chagas. Nesse aspecto, vale ressaltar que os quadrinistas primam em apresentar histórias locais ou do universo de preocupações do brasileiro, colaborando com o Caderno de forma espontânea, diferentemente dos diários locais, que despendem investimentos com pagamentos aos sindicatos norte-americanos para estampar quadrinhos de artistas estrangeiros.

Resumo: O artigo trata da trajetória do Jornal de Natal (RN), especialmente do suplemento cultural, Caderno de Encartes. Há dois anos o suplemento abre suas páginas à expressão de jovens artistas e à comunidade. É um espaço de resistência do jornalismo comprometido com a cultura local e com seus leitores. Exemplo ímpar em uma regiāo cujo controle dos meios de comunicaçăo permanece nas mãos de familias que detêm o poder político e econômico no Estado.

Palavras-chave: Caderno de Encartes, Jornal de Natal, poder político, oligarquia, comunidade
Abstract: The article deals with the trajectory of the Jornal de Natal (from the Northeastern state of Rio Grande do Norte), most especially of the cultural supplement, the Caderno de Encartes. During the past two years the supplement has been opening its pages to the presentation of young artists and to the community. This is a resistance space for journalism that has a commitment to local culture and to its readers. It is a unique example in a region in which the means of communication remain in the hands of families that have political and economic power in the State.

Keywords: Caderno de Encartes, Jornal de Natal, political power, oligarchy, community 